\title{
Knowing who likes who: The early developmental basis of coalition understanding
}

Article

Accepted Version

Platten, L., Hernik, M., Fonagy, P. and Fearon, R. P. (2010) Knowing who likes who: The early developmental basis of coalition understanding. European Journal of Social Psychology, 40 (4). pp. 569-580. ISSN 0046-2772 doi: https://doi.org/10.1002/ejsp.752 Available at https://centaur.reading.ac.uk/17511/

It is advisable to refer to the publisher's version if you intend to cite from the work. See Guidance on citing.

Published version at: http://dx.doi.org/10.1002/ejsp.752

To link to this article DOI: http://dx.doi.org/10.1002/ejsp.752

Publisher: Wiley

All outputs in CentAUR are protected by Intellectual Property Rights law, including copyright law. Copyright and IPR is retained by the creators or other copyright holders. Terms and conditions for use of this material are defined in the End User Agreement.

www.reading.ac.uk/centaur 
Central Archive at the University of Reading

Reading's research outputs online 
Knowing Who Likes Who: The Early Developmental Basis of Coalition Understanding

\author{
Lara Platten
}

University College London and The Anna Freud Centre

Mikolaj Hernik

University College London and The Anna Freud Centre

\author{
R. Pasco Fearon \\ University of Reading
}




\begin{abstract}
Group biases based on broad category membership appear early in human development. However, like many other primates humans inhabit social worlds also characterised by small groups of social coalitions which are not demarcated by visible signs or social markers. A critical cognitive challenge for a young child is thus how to extract information concerning coalition structure when coalitions are dynamic and may lack stable and outwardly visible cues to membership. Therefore the ability to decode behavioural cues of affiliations present in everyday social interactions between individuals would have conferred powerful selective advantages during our evolution. This would suggest that such an ability may emerge early in life, however, little research has investigated the developmental origins of such processing. The present paper will review recent empirical research which indicates that in the first two years of life infants achieve a host of social-cognitive abilities that make them well adapted to processing coalition-affiliations of others. We suggest that such an approach can be applied to better understand the origins of intergroup attitudes and biases.
\end{abstract}


Knowing Who Likes Who:

The Early Developmental Basis of Coalition Understanding

A crucial problem that any child faces when negotiating their way through a complex social environment is to distinguish friend from foe. Knowledge of group affiliation, such as knowledge of in- and out-group membership, can offer valuable predictive information about who will potentially be responsive, prosocial and trustworthy and who might be aggressive, uncooperative or duplicitous. Research indicates that, like adults, young children and even infants demonstrate biases based on broad group membership evident by outwardly visible (or audible) attributes such as accent, language (Kinzler, Shutts, DeJesus \& Spelke, 2009), and race (Kinzler et al., 2009; Bar-Haim, Ziv, Lamy \& Hodes, 2006; Dunham and Banaji, 2006; 2007). Most research to date on the development of intergroup cognition has focussed on out-group biases based upon factors such as these (see Dunham, Baron \& Banaji, 2008, for a review). However, only a fraction of the individual's day-to-day intergroup behaviour occurs on the level of such broad group membership. Like our close primate relatives, humans have evolved in moderately large social groups, probably composed of smaller subgroups held together primarily by the ties of kinship (Wrangham, 1989). In addition, other short-term or longer-term small-scale groups may also form between non-kin, based on principles of reciprocity and common interest (Harcourt \& De Waal, 1992; Dunbar, 1993). For the young child this poses a critical cognitive challenge - the fact that small group coalitions of conspecifics, often, if not typically, tend to be dynamic and lacking in outwardly visible cues to membership. 
Thus, many of the most relevant and important cues to group membership, and the interpersonal attitudes this may entail, can be found in quite subtle interactions that take place within or between small groups or coalitions of individuals in the child's social environment. That is, by observing social signals, emotional attitudes and interpersonal behaviours within a social network, the child can gather crucial information about coalition-structure. Hence the ability to decode and monitor individual social interactions indicative of coalition-affiliations is likely to be crucial for effective social functioning and an indispensable tool in the child's social cognitive repertoire. This capacity may be partially or even entirely independent of group cognition related to more explicitly demarcated groups which have been the focus of the majority of research.

Clearly, it would appear efficient and adaptive to learn about potential foes indirectly through observation or instruction rather than through first-hand experience. Extensive research indicates that primates are remarkably proficient in reading who is in a coalition with who based on such signals (see Cheney \& Seyfarth, 2005, for a review of “eavesdropping" in animals including primates), and this ability most likely conferred powerful selective advantages during primate and human evolution.

Understanding how infants and young children learn about affiliative and antagonistic relations between people in their environment is not only important for a general understanding of children's social-cognitive development, it may also shed light on the cognitive processes implicated in a number of important social phenomena, such as the formation of social cliques, bullying and in-group out-group prejudices regarding race or other social categories. Indeed, research with young school-children has shed light on how small peer-group affiliations can mediate aggression and bullying, which in many 
cases will not of course involve visible or symbolic signs of any explicit group membership (Nesdale, Milliner, Duffy \& Griffiths, 2009; Hodges, Boivin, Vitaro \& Bukowski, 1999). Hierarchical structure and the presence of small-group coalitions are universal characteristics of human society but their early developmental origins and the impact they may have on early social functioning are still relatively understudied.

However, there are some notable exceptions to this, and these have revealed evidence of the early development of social group phenomena such as hierarchy formation (Russon \& Waite, 1991; Ross, Conant, Cheyne, \& Alevizos, 1992; see also Ross \& Conant, 1992 for a review). Russon and Waite's (1991) classic ethological study for example identified a dominance hierarchy in 11-to-16 month old infants in a day-care group and showed that the position in such a hierarchy may determine whether the infant is more likely to imitate others or to be imitated.

Despite the relative lack of research focussing on the development of social cognition related to these kinds of social coalitions, the present paper will review recent empirical research which indicates that infants in the first two years of life at least possess a number of social cognitive abilities that make them well adapted to processing the coalition-affiliations of others. These abilities, we argue, are prerequisites for coalition processing, although the extent and timing of the development of coalition processing in the early years is still largely unknown.

To effectively interpret and track social interactions of this nature there are a number of prerequisite abilities the observer requires. Firstly, the successful tracking of social interactions requires the ability to understand the meaning, or valence, of observed behaviours between agents (e.g. whether an act is helpful or harmful). The observer must 
also understand the causal and referential structure of those acts (i.e. rather than just noticing that there was an offence, she needs to understand which party was the offender and which was the victim) and be able to identify individuals participating in these interactions and to track through time the causal and/or referential roles they played (i.e. who was the offender to whom and who was whose victim).

In summary, although consistent evidence of early group biases in childhood and infancy have been found, research investigating the development of social cognition among smaller coalitions of individuals lacking in visible markers remains rare. In an attempt to redress the limited volume of research focussed on social cognition at this level, we explore existing findings from infancy research which point toward the existence of abilities which, taken together, may form the basic building blocks of social coalition reasoning.

\section{The Evolution of Social Group Processing}

Like humans, our primate relatives are social creatures, living in groups based to a greater or lesser extent on kinship. Though varying from species to species, primate social structures are typically characterised by relatively strict social hierarchies, and resources of various kinds (e.g. dominance, access to mates) are often secured by those that are able to attract and maintain strong group or coalitions of cooperating individuals (Cheney \& Seyfarth, 1999). Their environment is rich in behavioural cues to social status, affiliations, and attitudes, and primates are adept at negotiating the complex dynamics of the groups that they inhabit. They are, for example, skilled at identifying individuals and their close-relatives - chimpanzees can correctly identify mother-offspring pairs where 
the pairs are made up of individuals they have never before encountered (Parr \& de Waal, 1999). The ability to identify individuals is clearly vital in order to track those involved in relatively stable social relations. We also know that non-human primates use facial and vocal expressions targeted at other individuals as indicators of interpersonal attitudes (Bergman, Beehner, Cheney \& Seyfarth, 2003; Seyfarth, Cheney \& Bergman, 2005). Further, Old World monkeys use such cues to encode highly specific and differentiated information concerning affiliations between individuals (kin and non-kin) that reflect differences in coalition membership or social rank, for example if A is dominant to B and B to C, then A is dominant to C (Seyfarth et al., 2005). In this way they are capable of developing quite complex models of hierarchies not only within but also between groups. Further, Old World monkeys adjust their social behaviour on the strength of interactions they witness between others from different social coalitions. For example, Cheney and Seyfarth (1999) found that baboons react aggressively towards a third party when exposed to a hostile interchange between a direct relative (a kin-based coalition) and a relative of the third party.

The capacity to use affectively valent behaviour to make person-specific attributions about a specific form of dispositional attitude - coalition-based affiliation and aggression - appears to be relatively evolutionarily ancient and is not specific to human cognitive adaptations. Thus, one may expect it to emerge early on in development, particularly considering the potential adaptive advantages associated with being able to decode behavioural cues relating to social affiliations and group membership. We suggest that research provides evidence that the abilities described in primates are already present in human infants before they enter their third year. Influential theorists have 
argued that tracking complex social networks related to coalitions was a primary

evolutionary factor in driving the expansion of the neocortex in primates (Dunbar, 1993).

Given its evolutionary significance, it is surprising that this capacity has not been extensively studied in developmental research.

In the following sections, we review studies that have examined early socialcognitive abilities that we think are the cognitive prerequisites for the ability to reason about social coalitions. We begin by examining studies that have addressed the development of infants' abilities to remember the identity of individuals - a necessary ability in order to track members of an affiliative relationship. We then review evidence about the emergence of skills for identifying emotion expressions and extracting their social meaning, which are among the most important social cues for signalling interpersonal attitudes. Finally, we consider research that indicates infants can attribute attitudes to patterns of social interaction even in the absence of direct expressions of emotion (e.g. non-verbal behaviour indicative of helping/cooperating, hindering or attacking).

\section{Tracking individuals - Infants ability to recognise faces}

In order to begin to learn the attitudes of individuals towards each other in their social environment, the young infant must be able to identify the individuals involved in an interaction so they can commit their expressed attitudes to memory. One way in which they may do this is through facial recognition. The 'specialness' of faces is a well researched area (see, for example, Nelson, 2001, for a review). Infants process faces differently to how they process objects (de Haan \& Nelson, 1999) and this differential processing appears early on in infancy (Halit, Csibra, Volein \& Johnson, 2004). Infants' 
ability to distinguish and recall faces develops early on and rapidly. At only $3-6$ days of age, infants discriminate between a novel face to one they have been familiarised to and this memory trace lasts for periods of at least two minutes (Pascalis \& de Schonen,1994). More recent findings suggest neonates are capable of remembering familiar faces for periods much longer than this, as demonstrated by a preference for their mother's face over a stranger's even following an absence of over 15 minutes by their mother (Bushnell, 2001). Indeed, faces seem to hold a special status in infant memory - 6-month-olds' memory for photographs of faces are more durable than for abstract black and white patterns, for example (2 weeks versus 48 hours respectively, Fagan, 1973). Furthermore, research we will discuss in more detail later shows that other factors, such as the actions of the individual concerned, can affect face recognition at least in 4-year-olds (Kinzler \& Shutts, 2008).

Infants' appear to engage in quite sophisticated face processing at an early age. For example, Pascalis, de Haan, Nelson and de Schonen (1998) habituated 3 and 6 month old infants to a face using a variety of poses rather than a repetition of a single pose and compared their preference for a novel face to the familiar face in yet another new pose. Following delays of both 2 minutes and 24 hours, 6 month old infants, and 3 month old male - but not female - infants demonstrated a preference for the novel face. The authors suggest this gender difference may reflect variation in developmental timing either in memory or in face-processing competencies between the sexes. Gender differences apart, the results indicate that even very young infants' face processing goes beyond simple pattern detection. 
A large body of recent neurological research has focussed on face processing in infants. EEG data has demonstrated, for instance, that differential processing of faces and objects appears early on in infancy (de Haan \& Nelson, 1999) and has identified brain correlates indicative of "recognition" in response to familiar faces. In Pascalis et al's (1998) previously mentioned research, 3-month-olds' recognition of the familiarised face after the shorter length delay was reflected in ERP data showing a large positive slow wave in response to presentation of a novel face, in contrast to brain activity that returned to baseline levels when presented with the familiar face. Likewise, infants' ERP data reveals differential responses to their mother's face than a novel female face (de Haan \& Nelson, 1999).

These brain correlates - and infants' ability to recognise a familiar face - are so robust that 6-month-olds show a greater Negative Central component to primed faces than novel faces when presented not only in an upright orientation but also when inverted (Webb \& Nelson, 2001). Recent research (Southgate, Csibra, Kaufman \& Johnson, 2008) with 6-month-old infants indicates that they also process changes in faces differently to changes in objects. In their study when a screen raised to obscure a face for a period of $500-800 \mathrm{~ms}$ was then lowered to reveal the same face again a decrease in gamma-band activity was recorded which was not observed when a novel face was revealed from behind the screen, most likely reflecting recognition. Furthermore, a decrease in gammaband activity was found when both old and new objects were revealed, thus providing further evidence that infants are particularly adept at processing and recognising facial stimuli in comparison to other stimuli. 
Infants' early expertise for facial identification may have significant consequences for the development of processing biases related to in-group and out-group status. Racial discrimination is an area on which much adult literature on inter-group attitudes has focussed. For example, the Implicit Association Test has shown that whilst white adults may explicitly disagree with prejudiced statements they may still evidence implicit negative associations towards black faces, and greater amygdala responses reveal more emotional processing for black than white faces by white participants (Cunningham, Johnson, Raye, Gatenby, Gore \& Banaji, 2004). Data suggests that the development of this in-group preference has its roots in infancy and is clearly a product of early socialisation. For instance, 3-month-olds demonstrate a preference for faces of their own race (Bar-Haim, Lamy \& Hodes, 2006) which is absent in newborns (Kelly, Quinn, Slater, Lee, Gibson, Smith, Ge \& Pascalis, 2005), and are better at recognising faces of their own race than other races (Sangrioli \& de Schonen, 2004), and this bias increases so that by 9 months a fully fledged 'other race' effect is present and infants only reliably discriminate between individual faces of their own race (Kelly, Quinn, Slater, Lee, Ge, \& Pascalis, 2007).

Taken together, these findings clearly indicate that the capacity to compute and remember facial identity develops rapidly in the first weeks and months of life. While there are clearly many different social functions that require facial identity recognition, a crucial one, we think, concerns the differing relationships these individuals have vis-à-vis the infant and the infant's immediate social group (e.g. nuclear family). Notably however, little research has examined to what extent infants can remember networks of individuals (who is associated with who - such as the members of a family network - or who likes 
who), although we review evidence later that indirectly indicates that infants are able to remember networks of at least three individuals over short periods of time early in the second year of life.

\section{Infant understanding of attitudes}

Infants' understanding of emotional expressions: Although there are many other behavioural cues to attitudes - some of which we will discuss later - infants' early expertise in processing facial stimuli must make emotional facial expressions an ideal starting point for gathering social information. Fridland (1994) emphasised the importance of emotional expressions as social tools, rather than merely a method of conveying the underlying mental state of the expressor. In support of this assertion, Yik and Russell's (1999) research with a cross-cultural sample of adults found that facial expressions convey social meaning almost as reliably as they do emotion (where the social meaning of an angry expression may be "back off or I'll attack" whilst the emotional message conveyed is "I'm really angry").

In terms of the development of emotional understanding, it has long been established that by the time they reach 3 months of age, infants can already discriminate between the facial expressions for the basic emotions of surprise, happiness and sadness (Young-Browne, Rosenfeld \& Horowitz, 1977). Later research using a paired presentation of a familiar and novel emotional expression, found that infants aged $4-6$ months successfully discriminated between angry, fearful and surprised facial expressions (Serrano, Iglesias \& Loeches, 1992). Further, this behavioural data is supported by results showing differential neurological responses according to the emotion 
expressed (Nelson \& de Haan, 1996; Lappänen \& Nelson, 2006; Lappänen, Moulson, Vogel-Farley \& Nelson, 2007).

The research discussed so far demonstrates that from a young age infants can identify different faces and can discriminate one emotional expression from another. Moreover, there is evidence that they can successfully interpret and learn from such expressions. For instance, by 18 months infants successfully predict other's preferences even when they conflict with their own - by using valence information contained in emotional expressions (e.g. Repacholi \& Gopnik, 1997). Further, some recent proposals (Gergely \& Csibra, 2006; Csibra \& Gergely, 2009) suggest that emotional expressions produced in a communicative context are a method by which culturally held information may be transmitted.

To summarise, emotional expressions convey important social information in addition to internal emotional states. Infants have an early sensitivity to facial stimuli, and given their ability to distinguish between expressions on the basis of emotional valence, it would be a reasonable to suggest that facial emotional expressions may be the earliest cues the infant utilises when beginning to navigate their social world. Further support for this claim comes from the studies on social referencing, discussed in the next section.

Social referencing: Studies of social referencing build upon previously reviewed evidence in that they indicate that infants can extract valenced social information from emotional expressions and use it to guide their own behaviour. In Sorce, Emde, Campos and Klinnert's now famous study (1985) 12 month old infants were presented with a visual cliff - a plexiglass table with a patterned, sloping layer beneath, giving the illusion 
of a shallow and deep side. The infant was positioned on the shallow side, with their mother at the deep side and an attractive toy between them on the deep surface, therefore creating ambiguity surrounding the perceived depth. Sorce et al. found that infants' level of approach behaviour to their mother and the toy varied according to their mother's emotional display, with the infant less inclined to approach following fearful and angry affect than following a happy and interested display.

Many studies have investigated the tendency of infants to moderate their behaviour according to displays of emotion. To give just a few examples, infants' approach behaviour towards novel toys (Hornik, Risenhoover \& Gunnar, 1987), rabbits (Hornik \& Gunnar, 1988) and, importantly, people (Feinman \& Lewis, 1983) is reduced following a negative emotional display by their mothers towards the target. Furthermore, when faced with an event that provokes uncertainty, infants will actively seek out information from those who are likely to be more knowledgeable (Zarbatany \& Lamb, 1985). However, variables such as identity of the knowledgeable other and the infant's own initial emotional reaction to the stimulus, appears to moderate how much this information influences their subsequent behaviour. The studies mentioned so far used a combination of facial and vocal expression, but it is of note that there is some evidence that affect communicated through the vocal channel alone can be sufficient for social referencing to occur (Mumme, Fernald \& Herrara, 1996).

That infants engage in social referencing provides evidence that they do not only discriminate between emotional expressions but that they attach some meaning or valence to the emotion in order for it to guide their subsequent behaviour. The findings also demonstrate a crucial point made earlier - that emotional expressions are far more 
than outward manifestations of mood. They are referential acts, produced by agents in reaction to events in their environment, and by understanding their referents, important social information can be extracted (Fridland, 1994; Yik and Russell, 1999). Therefore it is important that infants grasp the referential nature of emotional expressions and accurately identify the referent from an early stage of development, if they are to fully exploit the social cues in their environment.

Evidence that infants are already becoming skilled at understanding the referents of emotional expressions by the end of their first year comes from research findings that their play and exploratory behaviour varies according to not only the valence but also the specificity of their mother's emotional message. For example, a positive emotional message (expressed through both the vocal and facial channels) toward a novel toy lead to increased play with the toy and decreased exploration of the room, whilst a positive emotional message expressed more generally (through the facial channel only) lead to decreased levels of play with the same toy and increased exploration of the room as a whole (Stenberg \& Hagekull, 1997). In the absence of referential cues infants as young as 12 months do not make a blind association between an emotional expression and an object to which they just happen to be attending: their behaviour towards a toy was not affected by a verbal expression of disgust by an out of view experimenter (Moses, Baldwin, Rosicky \& Tidball, 2001). Taken together (see also review by Baldwin \& Moses, 1996) these results provide strong evidence of early referential understanding of emotional expressions by the end of the first year of life. Furthermore, recent research appears to have identified differential brain responses to an object which has been the target of a fearful emotional expression by an adult in infants as young as 3 months of 
age (Hoehl, Wiese and Striano, 2008). Although this does not imply that referential emotional understanding is in place at this age, it does indicate that referential cues related to emotion may bias object processing, which may be an early forerunner of this more sophisticated capacity.

Importantly, it is not just the more obvious emotional signals typical of social referencing studies that infants are sensitive to. In a study by de Rosnay, Cooper, Tsigaras and Murray (2006), despite not having received direct communication from their mother, twelve to 14-month-olds were more fearful and showed higher avoidance towards a stranger with whom their mother had interacted in a socially anxious (reticent, nervous) manner as opposed to one she was instructed to act normally with. This indicates that even when the emotional cues present are more subtle, infants may still be sensitive to such cues and use them to inform their own attitudes. One of the challenges of interpreting these studies of course is that it is not always possible to discriminate between an infant's changed attitude to a target, and a lower-level mechanism involving, for example, generally negative arousal, which then leads to avoidance or inhibited behaviour (cf. Stenberg \& Hagekull, 1997).

Whether infants willingly engage in social referencing with any adult has been questioned. The majority of studies have relied upon the emotional expressions of the infants' mothers. As mentioned previously, research has shown that when faced with an uncertainty-provoking event, infants will seek information from adults who are present, even if they are strangers (Zarbatany \& Lamb, 1985). However, there is evidence that infants differentiate between sources, with displays by their mothers having greater bearing on their behaviour than those of a female stranger. It is tempting to infer that 
these effects reflect dispositional differences in some early prototype of trust, related perhaps to the affiliative relationship between the infant and the expressor. However, these differences can also be explained by mere differences in familiarity of the source, if not by the different emotional responses provided. The question arises however, regarding the point in development at which validation of the source starts being a mediating factor in social referencing and in communication. Informant's benevolence, intention to deceive, previous inaccuracy or ignorance can affect how her testimony is received by young preschoolers (Harris 2007; Mascaro \& Sperber, 2009).

However, in certain circumstances at least, infants may rely upon strangers for social referencing. Klinnert, Butterfield and Campos (1986) found that 12-month-old infants engaged in social referencing with an experimenter in the presence of their mother. They suggest that one factor which may have influenced the infant's willingness to social reference with a relative stranger may be the positive exchange between the mother and the experimenter prior to the social referencing episode. If this is the case, then it raises the possibility that infants may recognise or assume that their friend's ally (or in this case, their mother's ally) is likely to be their ally too, a strong sign of coalition-based reasoning. Using this logic, infants could potentially begin to build networks of trusted individuals allied to their caregivers or allies, i.e. their immediate 'in-group', and identify those excluded from such alliances, which may form the earliest social-cognitive basis of the identification of out-groups. An alternative plausible explanation though is that their mother's presence made infants more relaxed and secure, and therefore more open to social referencing with a novel person. To distinguish between these two theories further research is necessary, however our discussion of the procedure at least illustrates how 
social-referencing paradigms could be used to further inform our understanding of the development of coalition-processing abilities.

In conclusion, moving on from infants' early developing ability to identify and track individuals through face recognition, and to discriminate between emotional expressions as one potential cue to attitudes, we suggested that social referencing studies provide vital evidence of infants' relatively advanced ability to decode simple and subtle social cues. They are able to utilise information conveyed not only through emotional expressions manifested for their benefit but also more subtle behavioural cues to emotion in interactions that they witness. They also grasp the referential nature of such expressions and accurately identify their target. Further, they will actively seek out information from knowledgeable others (adults) - preferably one who is trusted - when it is needed, in order to form their own attitude toward a target.

We believe that the clearly sophisticated ability of young infants to read and interpret the referential attitudes of trusted others and to attach valence information to objects and people in the world around them may represent a basic early-emerging mechanism via which infants collect information about coalition structure. By reading the subtle expressive and bodily signals that are directed at novel agents by adults within their coalition (initially primary caregivers) infants begin to learn about who can be trusted and be expected to behave in a cooperative and prosocial way and those who cannot. These very early sensitivities may provide one mechanism via which a lack of trust towards single individuals, small groups or, later, whole classes of people within a child's environment may develop. Research (de Rosnay et al., 2006) also indicates that the relevant signals may be quite subtle, reflecting mild signs of caution or anxiety 
(Kaltenbach, Weinraub \& Fullard, 1980) rather than overt hostility or fear, but still remain perceivable by the infant.

\section{Extracting Valence Information from Social Behaviours}

Stronger evidence that infants' abilities to assign valence to others is not restricted to emotional expressions, but may extend to whole social acts or behaviours, comes from studies using habituation methodologies. In a classic study by Premack and Premack (1997) twelve-month-old infants were habituated to animations depicting positive or negative interactions (“caressing", "helping", "hitting” or "hindering") between two abstract agents - a grey and a black circle. In the test phase infants were shown an animation where the grey agent "hit" the black agent. Of most interest is that not only those infants who had been habituated to a "caressing" animation demonstrated greater dishabituation to this test movie than those who had seen "hitting", but those who had been habituated to a "helping" behaviours also dishabituated more than those shown "hindering" animations. These results would indicate that infants not only habituated to the initial acts, but also to their socially-defined or manifested valence. Thus, a general interpretation of this study is that by 12 months infants link, cognitively, social acts of aggression with predictions of non-cooperation or hindrance, and conversely they predict that caregiving behaviour occurring between novel (to the infant) third parties is likely to be accompanied by cooperation between them.

Further evidence of this form of third-party interpretation of social interactions comes from work by Hamlin, Wynn and Bloom (2007), who presented infants with a puppet show in which a circular agent was seen attempting, and failing, to climb a hill, in the presence of two bystander shapes - a triangle and a square. As the climber struggled 
to reach his goal, one of the shapes swooped down and either helped the circular agent by pushing it to the top of the hill, or hindered the circle by pushing it back down to the bottom. In the following trial they saw the other agent carry out the opposite action. What the infants witnessed evidently affected their own attitudes towards the characters - when subsequently presented with the helper and the hinderer and encouraged to choose one, both 6- and 10-month-old infants showed a reliable preference for the helping character.

Further research from the same group sheds more light on infant's expectations about social alliances from their social observations. In Kuhlmeier, Wynn and Bloom (2003), animations of the helping and hindering events seen in Hamlin et al. (2007) were followed by a test movie in which the infant saw the circle approach and settle beside either the shape which had hindered it or had helped it. The infants' looking times to these two outcomes indicated that they differentiated between them. In yet another version of this study summarised by Wynn (2008) infants showed increased looking when the circle chose to be with the shape which had previously been seen to hinder it inferred to be a function of the violation of the infants' expectations about reciprocity in social interactions. This series of intriguing studies still leaves unanswered many questions which are crucial from a coalition-processing perspective: e.g. do infants evaluate the hinderer and the helper as universally mean or benevolent or do they rather represent social relationships observed as specific to particular dyads of agents?

The ability to decode valence information contained in simple interactions such as those described above would have important evolutionary value for identifying potential threats in the social environment. In support of this theory, Kinzler and Shutts (2008) found that 4 year olds showed enhanced recognition for individuals who had committed a 
harmful action relative to helpful individuals. Further, 4 year olds did not show increased recognition for recipients of harmful acts over recipients of helpful acts, suggesting that such differences in the first experiment were not driven by generally better memory for negative events but by the motivation to detect and remember potentially threatening individuals. From a coalition perspective, it would of course be interesting to know what these children encoded about the recipients of the harmful or helpful acts, including their likely reaction to re-encountering the respective individuals again. The most discriminating test of the availability of coalition-based representations would require the same agent to help and hinder different individuals, which would then rule out any generalised negative or positive attitudes the child might develop to the agent in question and allow one to assess relational information (who likes who, who doesn't like who).

However overt aggression or helping are not the only valuable behavioural cues of coalition-affiliations. A primitive social act such as chasing is both universally understood and recognized in extremely impoverished abstract stimuli (Barrett, Todd, Miller \& Blythe, 2005; Gao, Newman \& Scholl, in press), and its causal structure is also represented by infants as young as 8 months of age (Schlottmann, Surian \& Ray, 2009; Rochat, Striano \& Morgan, 2004). This is evident in infants' dishabituation to the reversal of the causal roles observed previously, i.e. when the former chaser becomes the chased and vice versa. By the end of their first year of life the infant can also accurately predict the outcome of the chasing sequence (i.e. that the chaser arrives at the chasee rather than passing him by) as long as the chaser pursues its target efficiently given situational constraints (Csibra, Bíró, Koós \& Gergely, 2003; Wagner \& Carey, 2005; Southgate \& Csibra, in press). 
Moreover according to some theorists (Luo, Kaufman \& Baillargeon, 2009), even most basic actions such as approaching a target by an agent (Luo \& Baillargeon, 2005; Shimizu \& Johnson, 2004; Johnson, Shimizu \& Ok, 2007) are represented by young infants in a way which, arguably, may play a key role in development of attitudeattributions to the agent. After witnessing an agent repeatedly approaching the same one of two target-objects 5-month-olds expect the agent to continue approaching the same object after the targets' locations were swapped. However, they do not form such an expectation if the object which was repeatedly approached was initially the only potential target present (Luo \& Baillargeon, 2005). In other words, a simple target-directed approach may be understood from very early on as an expression of the agent's preference. When applied to observed social interactions of third parties, the two early cognitive abilities outlined above may prove to be a powerful tools for analysing the social environment by generating representations which spell out who prefers to approach who and who is being chased away by who. As infant social cognition is one the most vibrant research areas in developmental psychology future studies are very likely to address questions about early developmental roots of other skills relevant to coalition processing now documented only in preschool-aged children, such as sensitivity to behavioural patterns suggestive of ostracism (Over \& Carpenter, 2009) to facial features cueing to dominance (Keating \& Bai, 1986) and to some of the factors affecting trustworthiness of the source of information (Harris, 2007; Mascaro \& Sperber, 2009).

In summary, evidence suggests infants can interpret the social interactions of others - interactions that the infant is an observer to, and which have no direct consequence for the infant - and form expectations about the behavioural consequences, 
for example, whether an alliance between two parties is likely or unlikely. By linking collections of individual coalitions and rivalries, the infant could - in theory - begin to build whole networks of knowledge about social in-groups and out-groups, and eventually make relational computations of the form "the friend of my friend is my ally", or even that "the enemy of my friend may not be my ally". Little if anything is known about the development of such abilities in early development, and hence the topic is a potentially rich area for future research.

\section{Conclusion}

It is clear from research on primates that reasoning about the affiliative or antagonistic relationships between networks of individuals in a large social group, indicative of coalitions or dominance hierarchies, was an important feature of primate evolution. This ability to read who is 'in league' with who is clearly important socially, and arguably must form an important part of the basis of children's functioning and behaviour in social groups. It may also relate in systematic ways to the manner in which children acquire feelings and views about other social groups from the more or less subtle cues expressed by members of their family, or other coalition members. However, little research has directly addressed the developmental roots of such abilities. Nevertheless, experimental research in infancy provides good evidence that the prerequisite abilities identity memory (e.g. Fagan 1973; de Haan \& Nelson, 1999; Bushnell, 2001; Pascalis et al., 1998), emotion expression discrimination (e.g. Young-Browne et al., 1977; Nelson \& de Haan, 1996; Lappänen et al., 2007), valence interpretation of emotional expressions (e.g. Feinman \& Lewis, 1983; Sorce et al., 1985; Repacholi \& Gopnik, 1997) and referential interpretation of emotional expressions (e.g. Stenberg \& Hagekull, 1997; 
Moses et al., 2001; Hoehl et al., 2008), causal understanding (Schlottman et al., 2009;

Rochat et al., 2004) and valence interpretations of social behaviour (Premack \& Premack, 1997; Hamlin et al., 2007), are in place by the end of the second year, if not before.

This impressive list notwithstanding it has to be noted that any sum of prerequisite skills does not yet equal the actual full-blown ability to interpret the social environment as structured by small-group coalitions nor to understand the impact that affiliations with such groups have on others' actions. Research reviewed here provides evidence for the very early developmental basis of the mechanisms which are crucial for coalition understanding and thus gives substance to future search for early signatures of such cognitive processing. On the individual level, research may focus on children's ability to form simple inferences about alliances: e.g. at what age and under what conditions can they infer that a friend of an enemy is a potential foe.

A critical question also concerns the general extent to which infants and young children can make inferences about inter-personal relationships. For example, when do infants acquire the ability to recognise that relationships are properties specific to two (or more) individuals, and do not reflect dispositions that can be generalized to other social partners? When do infants recognise that relationships may be governed by principles of reciprocity, or that non-reciprocity or cheating threatens relationships and evokes retaliation? On the group level, more research may be needed looking for signs of early existence of alliances not just among peers (Ross et al, 1992; Ross \& Conant, 1992) but also within groups which include prominent adult members of the child's proximate social environment. Furthermore, a vital issue concerns the kinds of cognitive processes that underpin real coalitions (e.g. of peers) that children participate in. To do this, one 
must be careful not to assume that stable interactions between groups of infants, toddlers or children necessarily imply they have sophisticated knowledge about the structure of those interactions. For example, spontaneous, or even stable, aggregations of children could be driven by environmental factors or shared motivations (e.g. a group of children who enjoy playing with the same toys). In these circumstances, interacting together consistently over time may be explained without attributing complex knowledge about the structure of their group interactions (c.f. Goldstone, Roberts \& Gureckis, 2008).

Such research may enhance our ability to understand the developmental origins of prejudice, which may begin in the micro-social interactions that take place between individuals in the child's social environment. Related to this, an interesting question arises about how coalition-based processing interacts or intersects with processing based on visible markers of in-group and out-group status. We know, for example, that young school children may engage in biased thinking about out-groups based on experimentally introduced group indicators (e.g. Bigler, Jones \& Lobliner, 1997) and preschoolers show social biases based on overt cues such as race, language and accent (e.g. Kinzler at al, 2009) which may develop on the basis of biases already present in infancy (Kinzler, Dupoux, \& Spelke, 2007; Bar-Haim et al., 2006). There is thus clearly a relatively earlyemerging tendency toward group-level thinking in children. In attempting to understand the development of group biases in children (e.g. Bigler \& Liben, 2007), it may be beneficial to consider the way in which coalitions (e.g. friendships) interact with experimentally imposed group structures (see Wright, Aron, McLaughlin-Volpe \& Ropp, 1997, for an example with adults). Without doing so, studies may experimentally controlout effects related to social interaction and lose vital information about how relational 
knowledge interacts with group processes. A coalition perspective, for example, might point to interesting ways in which in-group-out-group cognitive biases may be permeable to relationship information based on emerging coalitions. From an applied perspective this approach, in line with classic findings in social psychology (e.g. Allport, 1954; Sherif \& Sherif, 1953; Wright et al., 1997) reaffirms the fact that mere exposure to individuals from different social groups may not be sufficient to promote affiliative behaviour between them unless there are active efforts to promote opportunities for reciprocal interactions or clear signalling of positively valenced attitudes (perhaps by influential members of the child's immediate coalition, e.g. parents, siblings). In that sense, understanding the mechanisms of coalition processing may provide important insights regarding the most promising targets of very early interventions designed to improve inter-group relations in childhood, be they small social cliques in the playground or larger group dynamics that play out in the community as a whole.

\section{Acknowledgements}

We thank two anonymous reviewers, as well as the editors, for their valuable feedback on an earlier draft of this manuscript. This work was supported by a grant from the Economic and Social Research Council (grant reference RES-062-23-0746), entitled "Domain Specific Systems in Infants' Processing of Emotion Expressions". M. Hernik was supported by a Marie-Curie Research Training Network 35975 DISCOS. 


\section{References}

Allport, G. W. (1954). The Nature of Prejudice. Reading, MA: Addison-Wesley.

Baldwin, D.A., \& Moses, L.J. (1996). The Ontogeny of Social Information Gathering. Child Development, 67, 1915-1939.

Bar-Haim, Y., Ziv, T., Lamy, D., \& Hodes, R. M. (2006). Nature and Nurture in OwnRace Face Processing. Psychological Science, 17 (2), 159-163.

Barrett, H. C., Todd, P. M., Miller, G., F., \& Blythe, P. W. (2005). Accurate Judgments of Intention From Motion Cues Alone: A Cross-Cultural Study. Evolution and Human Behavior, 26, 313-331.

Bergman T. J., Beehner J. C., Cheney D.L., \& Seyfarth R.M. (2003). Hierarchical Classification by Rank and Kinship in Baboons. Science, 302, 1234-1236.

Bigler, R. S., Jones, L. C., \& Lobliner, D. B. (1997). Social Categorization and the Formation of Intergroup Attitudes. Child Development, 68 (3), 530-543.

Bigler, R. S., \& Liben, L. S. (2007). Developmental Intergroup Theory: Explaining and Reducing Children's Social Stereotyping and Prejudice. Current Directions in Psychological Science, 16 (3), 162-166.

Bushnell, I. W. R. (2001). Mother 's Face Recognition in Newborn Infants : Learning and Memory. Infant and Child Development, 10, 67-74.

Cheney, D. L., \& Seyfarth, R. M. (1999). Recognition of other individuals' social relationships by female baboons. Animal Behaviour, 58, 67-75.

Cheney, D. L., \& Seyfarth, R. M. (2005). Social Complexity and the Information Acquired During Eavesdropping by Primates and Other Animals. In P. K. McGregor, Animal Communication. Cambridge: Cambridge University Press. 
Csibra, G., Bíró, S., Koós, S., \& Gergely, G. (2003). One-year-old Infants Use

Teleological Representations of Actions Productively. Cognitive Science, 27, 111133.

Csibra, G., \& Gergely, G. (2009), Natural Pedagogy. Trends in Cognitive Sciences, 13 (4), 148-153.

Cunningham, W. A., Johnson, M. K., Raye, C. L., Gatenby, J. C., Gore, J. C., \& Banaji, M. R. (2004). Separable Neural Components in the Processing of Black and White Faces. Psychological Science, 15 (12), 806-813.

de Haan, M., \& Nelson, C. A. (1999). Brain Activity Differentiates Face and Object Processing in 6-Month-Old Infants. Developmental Psychology, 35, 1113-1121.

de Rosnay, M., Cooper, P. J., Tsigaras, N., \& Murray, L. (2006). Transmission of Social Anxiety from Mother to Infant: An experimental study using a social referencing paradigm. Behaviour Research and Therapy, 44, 1165-1175.

Dunbar, R. I. M. (1993). Coevolution of Neocortical Size, Group Size and Language in Humans. Behavioral and Brain Sciences 16 (4): 681-735.

Dunham, Y., Baron, A. S., \& Banaji, M. R. (2008). The Development of Implicit Intergroup Cognition. Trends in Cognitive Sciences, 12 (7), 248-253.

Dunham, Y. \& Banaji, M. R. (2007, February). Poster presented at the $8^{\text {th }}$ Annual Meeting of The Society for Social and Personality Psychology, Memphis, TN.

Dunham, Y., \& Banaji, M. R. (under review). The Invariance of Intergroup Bias Across the Lifespan. Manuscript under review.

Fagan, J. F. (1973). Infants' Delayed Recognition Memory and Forgetting. Journal of Experimental Child Psychology, 16, 424-450. 
Feinman, S., \& Lewis, M. (1983). Social Referencing at Ten Months: A Second-Order Effect on Infants' Responses to Strangers. Child Development, 54 (4), 878-887.

Fridland, A.J. (1994). Human Facial Expression: An Evolutionary View. San Diego: Academic Press.

Gao, T., Newman, G. E., \& Scholl, B. J. (in press). The Psychophysics of Chasing: A Case Study in the Perception of Animacy. Cognitive Psychology.

Gergely, G., \& Csibra, G. (2006). Social Learning and Social Cognition: The Case for Pedagogy. In Y. Munakata \& M. H. Johnson (Eds.), Processes of Change in Brain and Cognitive Development. Attention and Performance, XXI. (pp. 249274). Oxford: Oxford University Press, 2006.

Goldstone, R. L., Roberts, M. E., \& Gureckis, T. M. (2008). Emergent Processes in Group Behavior. Current Directions in Psychological Science, 17, 10-15.

Halit, H., Csibra, G., Volein, Á., \& Johnson, M. H. (2004). Face-Sensitive Cortical Processing in Early Infancy. Journal of Child Psyhcology and Psychiatry, 45, 1228-1234.

Hamlin, J. K., Wynn, K., \& Bloom, P. (2007), Social Evaluation by Preverbal Infants. Nature, 450 (22), 557-560.

Harcourt A.H., \& de Waal F.B.M. (1992). Coalitions and Alliances in Humans and Other Animals. Oxford: Oxford University Press.

Harris, P. L.. (2007), Trust. Developmental Science, 10 (1), 135-138.

Hodges, E.V.E., Boivin, M., Vitaro, F., \& Bukowski, W.M. (1999). The Power of Friendship: Protection Against an Escalating Cycle of Peer Victimization. Developmental Psychology, 35, 94-101. 
Hoehl, S., Wiese, L., \& Striano, T. (2008), Young Infants' Neural Processing of Objects Is Affected by Eye Gaze Direction and Emotional Expression. PLoS ONE, 3 (6), 2389.

Hornik, R., \& Gunnar, M. R. (1987). A Descriptive Analysis of Infant Social Referencing. Child Development, 59 (3), 626-634.

Hornik, R., Risenhoover, N., \& Gunnar, M., (1987). The Effects of Maternal Positive, Neutral, and Negative Affective Communications on Infant Responses to New Toys. Child Development, 58 (4), 937-944.

Johnson, S.C., Shimizu, Y.A., \& Ok, S-J. (2007). Actors and Actions: The Role of Agent Behavior in Infants' Attribution of Goals. Cognitive Development 22, 310-322.

Kaltenbach, K., Weinraub, M., \& Fullard, W. (1980). Infant Wariness Toward Strangers Reconsidered: Infants' and Mothers' Reactions to Unfamiliar Persons. Child Development, 51, 1197-1202.

Keating,C., \& Bai, D. (1986). Children's Attributions of Social Dominance from Facial Cues .Child Development, 57, 1269-1276.

Kelly, D. J., Quinn, P. C., Slater, A. M., Lee, K., Ge, L., \& Pascalis, O. (2007). The Other-Race Effect Develops During Infancy. Psychological Science, 18 (12), 1084-1089.

Kelly, D. J., Quinn, P. C., Slater, A. M., Lee, K., Gibson, A., Smith, M., Ge, L., \& Pascalis, O. (2005). Three-Month-Olds, but not Newborns, Prefer Own-Race Faces. Developmental Science, 8 (6), F31-F36.

Kinzler, K. D., Dupoux, E., \& Spelke, E. S. (2007). The Native Language of Social Cognition. The Proceedings of the National Academy of Sciences of the United States of America, 104, 12577-12580. 
Kinzler, K. D., \& Shutts, K. (2008). Memory for "Mean" Over "Nice": The Influence of Threat on Children's Face Memory. Cognition, 107, 775-783.

Kinzler, K. D., Shutts, K., DeJesus, J., \& Spelke, E. S. (2009). Accent Trumps Race in Guiding Children's Social Preferences. Social Cognition, 27 (4), 623-634.

Klinnert, M. D., Emde, R. N., Butterfield, P., \& Campos, J. J. (1986). Social Referencing: The Infant's Use of Emotional Signals From a Friendly Adult With Mother Present. Developmental Psychology, 22 (4), 427-432.

Kuhlmeier, V., Wynn, K., \& Bloom, P. (2003). Attribution of Dispositional States by 12Month-Olds. Psychological Science, 14 (5), 402-408.

Lappänen, J. M., Moulson, M. C., Vogel-Farley, V. K., \& Nelson, C. A. (2007). An ERP Study of Emotional Face Processing in the Adult and Infant Brain. Child Development, 78 (1), 232-245.

Lappänen, J. M., \& Nelson, C. A. (2006). The Development and Neural Bases of Facial Emotional Recognition. In R. V. Kail (Ed.), Advances in child development and behaviour, Vol. 34 (pp.207-246). San Diego, CA: Academic Press.

Luo, Y., \& Baillargeon, R. (2005). Can a Self-Propelled Box Have a Goal? Psychological Reasoning in 5-Month-Old Infants. Psychological Science, 16, 601-608.

Luo, Y., Kaufman, L., \& Baillargeon, R. (2009). Young Infants’ Reasoning about Physical Events Involving Inert and Self-Propelled Objects. Cognitive Psychology, 58, 441-486.

Mascaro, O., \& Sperber, D. (2009). The Moral, Epistemic, and Mindreading Components of Children's Vigilance Towards Deception. Cognition, 112, 367-380. 
Mercier, H., \& Sperber, D. (2009). Intuitive and Reflective Inferences. In J. S. B. T. Evans \& K. Frankish (Eds.), In Two Minds. New York: Oxford University Press.

Moses, L. J., Baldwin, D. A., Rosicky, J. G., \& Tidball, G. (2001). Evidence for Referential Understanding in the Emotions Domain at Twelve and Eighteen Months. Child Development, 72 (3), 718-735.

Mumme , D. L., Fernald, A., \& Herrara, C. (1996). Infants' Responses to Facial and Vocal Emotional Signals in a Social Referencing Paradigm. Child Development, $67(6), 3219-3237$.

Nelson, C. A. (2001), The Development and Neural Bases of Face Recognition. Infant and Child Development, 10, 3-18.

Nelson, C. A., \& de Haan, M. (1996). Neural Correlates of Infants' Responsiveness to Facial Expressions of Emotion. Developmental Psychobiology, 29 (7),577-595.

Nesdale, D., Milliner, E., Duffy, A., \& Griffiths, J. A. (2009). Group Membership, Group Norms, Empathy, and Young Children's Intentions to Aggress. Aggressive Behaviour, 35, 244-258.

Over, H., \& Carpenter, M. (2009). Priming Third-Party Ostracism Increases Affiliative Imitation in Children. Developmental Science, 12 (3), F1-F8.

Parr, L. A., \& de Waal, F. B. M. (1999), Visual Kin Recognition in Chimpanzees. Nature, $399,647-648$.

Pascalis, O., \& de Schonen, S. (1994). Recognition Memory in 3- to 4-Day-Old Human Neonates. NeuroReport, 5, 1721-1724.

Pascalis, O., de Haan, M., Nelson, C. A., \& de Schonen, S. (1998). Long-Term Recognition Memory for Faces Assessed by Visual Paired Comparison in 3- and 
6-Month-Old Infants. Journal of Experimental Psychology: Learning, Memory, and Cognition, 24 (1), 249-260.

Premack, D., \& Premack, A. J. (1997). Infants Attribute Value \pm to the Goal-Directed Actions of Self-Propelled Objects. Journal of Cognitive Neuroscience, 9, 6, 848856.

Repacholi, B. M., \& Gopnik, A. (1997). Early Reasoning About Desires: Evidence From 14- and 18-Month-Olds. Developmental Psychology, 33 (1), 12-21.

Rochat, P., Striano, T., \& Morgan, R. (2004). Who is Doing What to Whom? Young Infants' Developing Sense of Social Causality in Animated Displays. Perception, $33,355-369$.

Ross, H., \& Conant, C. (1992). The Social Structure of Early Conflict: Interaction, Relationships, and Alliances. In C. Shantz \& W. Hartup (Eds.), Conflict In Child And Adolescent Development (pp. 153-185). Cambridge: Cambridge University Press.

Ross, H., Conant, C., Cheyne, J., \& Alevizos, E. (1992). Relationships and Alliances in the Social Interaction of Kibbutz Toddlers. Social Development, 1, 1-17.

Russon, A. E., \&Waite, B. E. (1991). Patterns of Dominance and Imitation in an Infant Peer Group. Ethology and Sociobiology, 13, 55-73.

Sangrioli, S., \& de Schonen, S. (2004). Recognition of Own-Race and Other-Race Faces by Three-Month-Old Infants. Journal of Child Psychology and Psychiatry, 45 (7), 1219-1227.

Schlottmann, A., Surian, L., \& Ray, E. D. (2009). Causal Perception of Action-andReaction Sequences in 8- to 10-Month-Olds. Journal of Experimental Child Psychology, 103, 87-107. 
Serrano, J. M., Iglesias, J., \& Loeches, A. (1992). Visual Discrimination and Recognition of Facial Expressions of Anger, Fear, and Surprise in 4- to 6-Month-Old Infants. Developmental Psychobiology, 25 (6), 411-425.

Seyfarth, M., Cheney, D. L., \& Bergman, T. J. (2005). Primate Social Cognition and the Origins of Language. Trends in Cognitive Sciences, 9 (6), 264-266.

Sherif, M., \& Sherif, C. W. (1953). Groups in Harmony and Tension: An integration of studies on intergroup relations. New York: Octagon.

Shimizu, Y.A., \& Johnson, S.C. (2004). Infants' Attribution of a Goal to a Morphologically Novel Agent. Developmental Science, 7, 425-430.

Sorce, J. F., Emde, R. N., Campos, J., \& Klinnert, M. D. (1985). Maternal Emotional Signaling: Its Effect on the Visual Cliff Behavior of 1-Year-Olds. Developmental Psychology, 21 (1), 195-200.

Southgate, V., \& Csibra, G. (in press). Inferring the Outcome of an Ongoing Novel Action at 13 Months. Developmental Psychology.

Southgate, V., Csibra, G., Kaufman, J., \& Johnson, M. H. (2008). Distinct Processing of Objects and Faces in the Infant Brain. Journal of Cognitive Neuroscience, 20 (4), $741-749$.

Stenberg, G., \& Hagekull, B. (1997). Social Referencing and Mood Modification in 1 Year-Olds. Infant Behaviour and Development, 20 (2), 209-217.

Wagner, L. \& Carey, S. (2005). 12-month-old Infants Represent Probable Ending of Motion Events. Infancy, 7, 73-83.

Webb, S. J., \& Nelson, C. A. (2001). Perceptual Priming for Upright and Inverted Faces in Infants and Adults. Journal of Experimental Child Psychology, 79, 1-22. 
Wrangham. R. (1982). Mutualism, Kinship and Social Evolution. In King's College Sociobiology Group (Eds.) Current Problems in Sociobiology (pp. 269-289). Cambridge: Cambridge University Press.

Wright, S. C., Aron, A., McLaughlin-Volpe, T., \& Ropp, S. A. (1997). The Extended Contact Effect: Knowledge of Cross-Group Friendships and Prejudice. Journal of Personality and Social Psychology, 73 (1), 73-90.

Wynn, K. (2008). Some Innate Foundations of Social and Moral Cognition. In P. Carruthers, S. Laurence, \& S. Stich (Eds.). The Innate Mind: Foundations and the future (pp. 330-347). Oxford, England, Oxford University Press.

Yik, S. M., \& Russell, J. A. (1999). Interpretation of Faces: A Cross-cultural Study of a Prediction from Fridlund's Theory. Cognition and Emotion, 13 (1), 93-104.

Young-Browne, G., Rosenfeld, H. M., \& Horowitz, F. D. (1997). Infant Discrimination of Facial Expressions. Child Development, 48 (2), 555-562.

Zarbatany L., \& Lamb, M.E.(1985). Social Referencing as a Function of Information Source: Mothers Versus Strangers. Infant Behaviour and Development, 8, 25-33. 